\title{
Nano and microhardness testing of heterogeneous structures
}

\author{
S. Baskutis*, V. Vasauskas ${ }^{* *}$, A. Žunda*** \\ *Kaunas University of Technology, Studenty str. 56, 51424 Kaunas, Lithuania, E-mail: saubask@ktu.lt \\ **Kaunas University of Technology, Studentu str. 56, 51424 Kaunas, Lithuania \\ ***Aleksandras Stulginskis University, Studentu str. 11, 53361 Kaunas region, Lithuania, E-mail: audrius.zunda@asu.lt

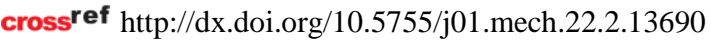

\section{Introduction}

Indentation methods, as remarkably flexible mechanical tests, are finding increasing use in the study of mechanical properties of bulk and thin film nonhomogeneous materials over a wide range of size scales [1]. Most engineering materials are of heterogeneous structure, different phase properties and facing dynamic changes. Therefore, the control of the local microstructure is especially important aiming to attain the macro scale properties. Instrumented indentation is an important tool that can be used to evaluate the mechanical properties of a wide range of engineering materials across the nano and micro length scales. By using the different shapes of indenters tip geometry and varying the applied load, indentation techniques can be used to probe different volumes of materials [2]. Correlation between the hardness and the microstructure in weld joints has been established for engineering materials [3].

The nanoindentation technique allows rather small regions in grains to be investigated and different phase structures are distinguished using this technique [4]. For low load nano and microindentation, the area of contact between the indenter and material varies during testing and is indirectly dependent on the measured depth of penetration. Micro and nanoindentation tests, i.e. indentation depths of 0.1 to $100 \mu \mathrm{m}$ and less than $0.1 \mu \mathrm{m}$, respectively, proved to be the most cost-efficient, as well as fast, precise and non-destructive insert. However, there are numerous indentation tests at scales on the order of a micron or a submicron that have shown that the measured hardness increases significantly with decreasing the indentation size $[5,6]$. This phenomenon is commonly referred to as the indentation size effect (ISE) [7]. The behaviour of the ISE in single crystals for nano and microindentation was investigated by Manika et.al. [8]. Association of the ISE with friction and with strain hardening was confirmed by M. Atkinson [9].

According to [10], ranges of hardness testing are defined: macro scale - test force diapazon $2 \mathrm{~N}-30 \mathrm{kN}$, micro scale - test force less than $2 \mathrm{~N}$, indentation depth more than $0.2 \mu \mathrm{m}$, nano scale - test force less than $0.3 \mathrm{~N}$, indentation depth less than $0.2 \mu \mathrm{m}$. The micro scale distinguished by the test force in relation to the indentation depth. For the nano scale, the mechanical deformation strongly depends on the real shape of indenter tip. Homogeneity in the material could be an important issue particularly in composite, where the indenter tip may be or may not be hit the particle and this could change the values of material properties.

The effects on the localization of deformation at various scales ranging from the microscales down to the nanoscales are discussed for heterogeneous structures. At the nanoscale, a dominant mechanism of deformation is the rearrangement of free nano volume and exchange of momentum between bulk and grain boundary space. At the microscale, a most common mechanism of deformation is dislocation motion [11]. Investigations developed by L.Qian et.al. [12] showed that nanoindentation and microindentation hardness tests have similar load effect and their differences are between $10 \%$ and $30 \%$. Correlation aspects between nanoindentatrion hardness tests results and Vickers hardness was described by T. Sawa [13]. It should be noted, that nanoindentation hardness and corresponding Vickers hardness values are different. This difference scale is because of the different manner the hardness values are defined. Nanoindentation hardness is determined using the indenter under load, while Vickers hardness is calculated after the load is removed.

The presented work deals with relatively more reliable and accurate hardness analysis in heterogeneous structures engineering. The nano and microindentation of polycrystalline copper thin films of different thickness and approximately the same grain size and carbon steel specimens, welded by gas tungsten arc welding (TIG), were used for the experiments.

\section{Background}

Nano and microindentation methods often are presented together and it seems to be simple and similar. In fact, process of indentation is very complicated regarding the deformation mechanism as well as the changes in the material structure under the indenter. The trend of nanohardness and microhardness profiles in the intermediate area between the inner layers with constant hardness and abnormal area gives information on structural heterogeneity [14]. This is the area where the ISE in indentation measurements can be demonstrated $[15,16]$. The idea, which enables the assessment of the homogeneity of the samples, was proposed and described in this article. Furthermore, many materials and especially structural ones exhibit phase heterogeneity and mechanical differences of the phases on different length scales. In order to model heterogeneous material systems, multi-scale approach that allows for separation of scales based on some characteristic dimension of a material microscopic feature for each level is often utilized. Averaged (effective) composite properties can be found if the indentation depth is much larger than the characteristic phase dimension $(h>>D)$. In this case averaged properties are obtained. If the $(h<<D)$, intrinsic properties of the distinct phase are obtained. Since Vickers tips cause 
relatively negligible strain in the material during indentation, the hardness results obtained from test using the different tip geometries can be directly compared. However, care must be taken to correctly perform the conversion of the results. There is a definition change between the hardness measured using microindentation to the hardness used in nanoindentation. While both hardness values are calculated as the peak force divided by the area of contact, the definition of the contact area differs between the test techniques [15]. For microindentation, the contact area is the surface area of the tip that area in contact with the sample. While, for nanoindentation the contact area defined as the projected area between the sample and tip. In nanoindentation the hardness is determined as the mean contact pressure. The nanoindentation hardness of the specimen can be analysed by the curves with the Oliver-Pharr method [1]. The conventional hardness:

$$
H(h)=\frac{F(h)}{A_{c}(h)}
$$

and the differential hardness:

$$
H_{d}(h)=\frac{d F}{d A_{c}}
$$

where $F$ is load, $A_{c}$ is indentation area, are calculated as continuous functions of the depth $h$ and compare to each other in this paper. It turns out that $H_{d}$ describes the momentary material resistance to deformation, whereas $H$ integrates our deformation states from first tip sample contact to current penetration $h$. This difference is important for materials not homogeneous in depth, e.g. layer systems.

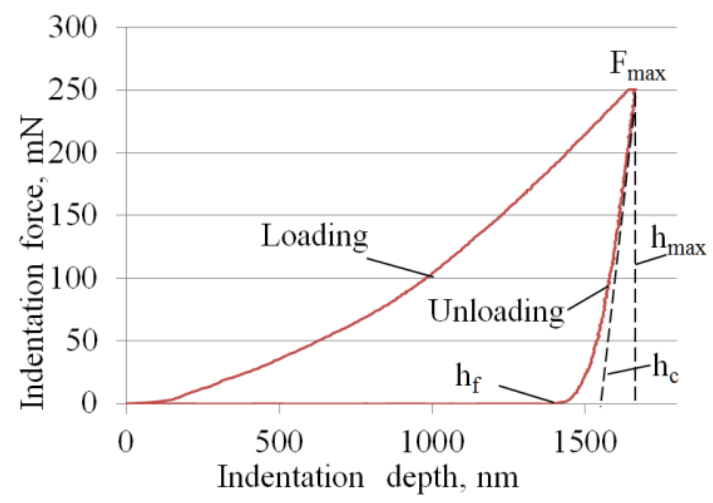

Fig. 1 Depth-force correlation for an indent at maximum force of $250 \mathrm{mN}$ with characteristic quantities: maximum indentation depth $h_{\max }$, final indentation depth $h_{f}$ and contact indentation depth $h_{c}$

The nanoindentation hardness $\left(H_{\text {nano }}\right)$ can be calculated using following formula:

$$
H_{\text {nano }}=\frac{F_{\max }}{A_{c}\left(h_{c}\right)},
$$

where in equation $F_{\max }$ is the peak indentation load, $A_{c}$ is the cross-sectional area and $h_{c}$ represents the contact indentation depth between the indenter and the specimen (Fig. 1). The determination of the contact indentation depth $h_{c}$ is obtained from equation:

$$
h_{c}=h_{\max }-0.75-\frac{F_{\max }}{S},
$$

where $S$ is the contact stiffness and can be obtained by:

$$
S=\frac{d F}{d h},
$$

where $d F / d h$ is the stiffness at the upper portion of the unloading data calculated from the slope of the depth-force curve.

The microindentation of tested samples had a larger scatter due to the influence of several factors: hardness of grains $\left(H_{\text {nano }}\right)$, ISE, microstructure and grain boundary phase and at higher loads by "mix-phase" volume below the indenter.

\section{Experimental}

Two types of heterogeneous materials were used in present study. At first, carbon steel was welded by using gas tungsten arc welding method, in the $\mathrm{Ar} / \mathrm{CO}_{2}$ protective gas environment, with the non-fusible electrode from tungsten, and second, copper $(\mathrm{Cu})$ films were made by electrospark deposition (ESD) on steel substrates. The specimens were deposited using $3 \mathrm{~A}$ current and sparking voltage of $60 \mathrm{~V}$. Film thickness was varied by changing the deposition time. In this paper we examined copper films of thickness $60 \mu \mathrm{m}$ and $120 \mu \mathrm{m}$.

Welding experiments were carried out under different welding regimes: current and voltage. The welding with non-fusible electrode required relatively large density welding current, therefore, small diameter $(0.8 \mathrm{~mm})$ welding wire, which was fed into electric arc by a relatively high feed rate. The welds were cross sectioned for microexamination under the microscope. The process of preparation of microsections involved three steps: cutting, mechanical polishing and etching. The abrasive water jet technology, which provides the possibility to eliminate the heat load, was used for the specimens' preparation.

Vickers microhardness and depth sensing indentation tests were performed using the prepared metallographic specimens. The properties in both nanolevels and microlevels were characterized using Nano-Hardness Tester developed by CSM Instruments, Switzerland. Indents were performed over a range of loads from 7 to $250 \mathrm{mN}$. We used a constant strain rate setting $1 / P(d P / d t)$ to be $2 \mathrm{~min}^{-}$ ${ }^{1}$ and a pause of $10 \mathrm{~s}$ was set at maximum load.

The layered substrate film system is not completely equivalent to the disordered structural multiphase materials but it can be successfully used as the first estimation. Microstructure was analysed using optical microscope Nicon Eclipse 1000 with magnification from $\times 50$ to $\times 1000$.

For microhardness and nanohardness investigations, identical specimens and areas have been used. However, it should be noted, that exactly the same grains of heterogeneous structures can't be investigated, but similar properties in adjusted regions of the microstructure are assumed. Microhardness has been measured on the fine and coarse-grained structures of both samples which were compared to the nanohardness measurements. Scratch test was made by CSM Nano-Scratch Tester using continuous- 
ly increasing load from 5 to $2500 \mathrm{mN}$. A scratch length of $4 \mathrm{~mm}$ has been used.

The specimen showed high plasticity and excellent adhesion (Fig. 2) with no adhesion cracks.

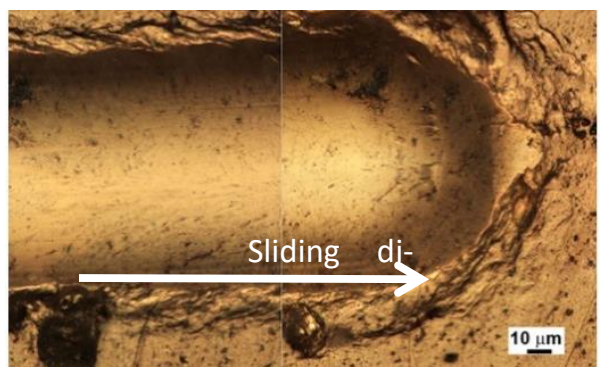

Fig. 2 Total view of the scratch-track of copper coating on steel substrate

Neither failure to a bigger extent nor complete exposure of substrate occurred within the predetermined range of normal load.

\section{Results and discussion}

The area of heat affected zone (HAZ) of welded joints basically depends on heat input and thermal conductivity of base metal. The boundary between the fuse zone and HAZ is clear to identify (Fig. 3) as the crystals in the first are dendrites and in the second globular. Due to recrystallization process, two different zones of HAZ can be observed, viz., HAZ1 and HAZ2. HAZ1 has coarse grains while HAZ2 has fine grains. Size and shape difference of grains is due to the distance from the weld.

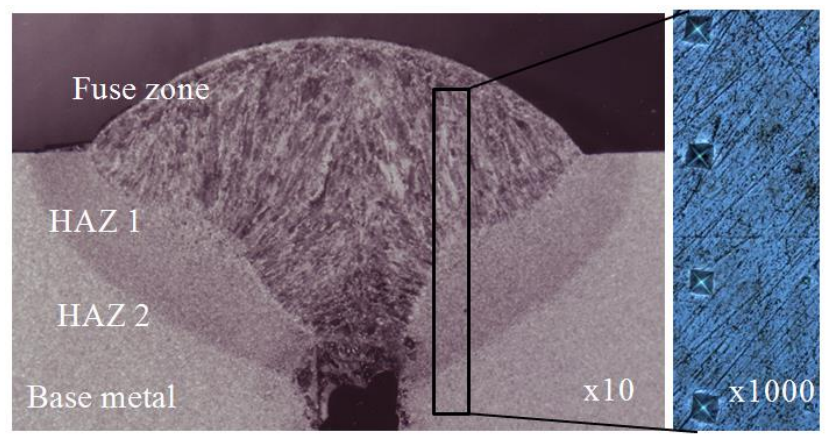

Fig. 3 Cross-sectional macrographs of the different zones of the TIG weld

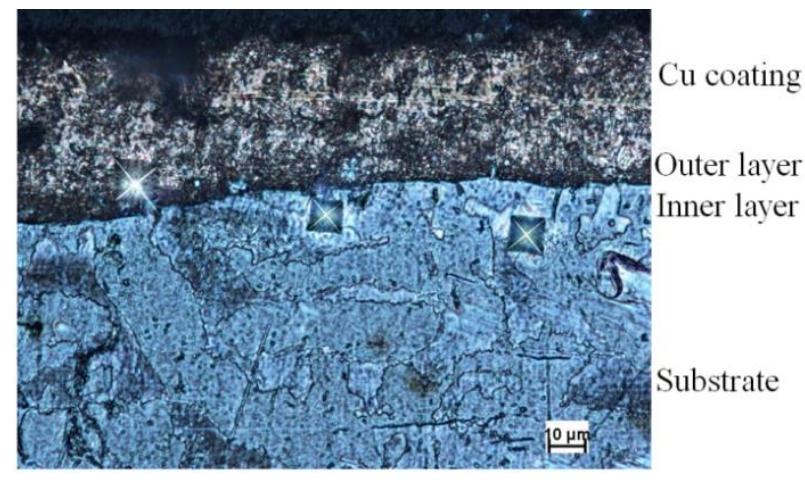

Fig. 4 Cross section of electro-spark $\mathrm{Cu}$ coating with the thickness of $60 \mu \mathrm{m}$

Cross section image of $\mathrm{Cu}$ electro-sparking coat- ing with thickness of $60 \mu \mathrm{m}$ on steel substrate, layers zones as well as indents of hardness testing are shown in Fig. 4.

Different indentation data may be obtained analysing different perpendicular cross sections of the weld. Approximately $10 \%$ variation of the nano and microindentation hardness data measured on the longitudinal cross section was observed. This fluctuation of the hardness values along the weld structure centreline is not uniform. Microhardness values were influenced by elastic recovery whereas nanohardness readings were not affected by plasticity. Microhardness was also more affected by grown of grains, than nanohardness.

Table 1, Fig. 5, Fig. 7 and Fig. 8 show the relationship between microhardness and nanohardness. The linear regression equation for this relationship is $H_{\text {nano }}=1.22 \mathrm{HV}$, where $H_{\text {nano }}$ is the nanohardness value in $\mathrm{MPa}$ and $H V$ is the microhardness value.

Table 1

Summary of the average values of nanohardness and microhardness in different zones of the specimens

\begin{tabular}{|c|c|c|c|c|c|c|}
\hline $\begin{array}{c}\text { Speci- } \\
\text { men }\end{array}$ & Zones & $\begin{array}{c}\text { Nano- } \\
\text { hardness }\end{array}$ & \multicolumn{2}{|c|}{ Microhardness } & \multicolumn{2}{|c|}{ Relation } \\
\hline \multirow{4}{*}{$\begin{array}{c}\text { Wel-ding } \\
\text { (TIG) }\end{array}$} & & $7 \mathrm{mN}$ & $50 \mathrm{mN}$ & $250 \mathrm{mN}$ & $\begin{array}{c}H_{\text {nanol }} \\
\text { HV50 }\end{array}$ & $\begin{array}{c}H_{\text {nanol }} \\
\text { HV250 }\end{array}$ \\
\cline { 2 - 7 } & Base metal & 308 & 339 & 269 & 0.91 & 1.14 \\
\cline { 2 - 7 } & HAZ2 & 298 & 335 & 264 & 0.89 & 1.13 \\
\cline { 2 - 7 } & HAZ1 & 316 & 352 & 299 & 0.90 & 1.06 \\
\cline { 2 - 7 } & Fuse zone & 361 & 402 & 340 & 0.90 & 1.06 \\
\hline \multirow{4}{*}{$\begin{array}{c}\text { Clad- } \\
\text { ding } \\
\text { (ESD) }\end{array}$} & Cu coating & 94 & 81 & 105 & 1.16 & 0.90 \\
\cline { 2 - 7 } & Outer layer & 254 & 230 & 208 & 1.10 & 1.22 \\
\cline { 2 - 7 } & Inner layer & 313 & 300 & 295 & 1.04 & 1.06 \\
\cline { 2 - 7 } & Substrate & 259 & 256 & 238 & 1.01 & 1.09 \\
\hline
\end{tabular}

As follows from Table 1, the fuse zone has a smaller indentation depth, i.e. higher hardness because it contains larger amounts of alloying elements such as silicon, carbon, and manganese.

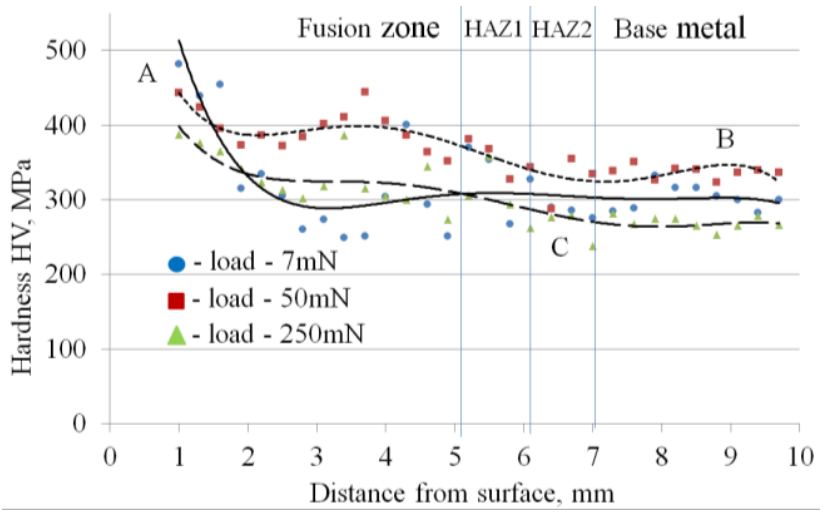

Fig. 5 Hardness values across the welded region vertically from the surface of fuse zone

HAZ2 zone also distinguished by the microhardness values, thus confirming that the microhardness reduction was influenced by self-tempering.

Fig. 5 shows a nano and microhardness profiles obtained across the welded region from the fuse zone through the unaffected base metal. Tests were carried on three specific locations: fuse zone at $A$, base metal at $B$ and $\mathrm{HAZ}$ regions at $C$ with reference to Fig. 5. A reduction in hardness (softening) with respect to base metal (avg. 
$300 \mathrm{HV}$ ) was clearly revealed in the sub-critical HAZ.

Apparent Vickers microhardness values $H V$ were calculated at each load using conventional approach

$$
H V=\frac{1.8544 P}{d^{2}},
$$

where $d$ is the average diagonal length of the Vickers indentation impression and $P$ is the indentation test load.

Clear ISE was observed in all of the samples that were tested. The ISE means the increase of indentation hardness with the decrease of indentation depth, which is close related with load. Particularly it was clear for determining hardness values of base metal as homogeneous structure (Fig. 6)

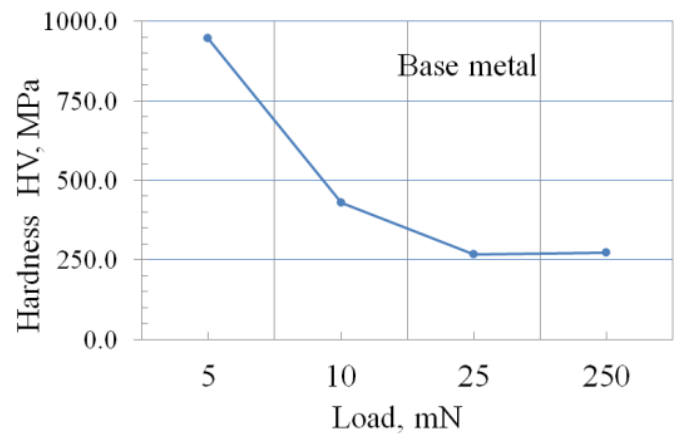

Fig. 6 Hardness of base metal measured by conventional method

The hardness increases while decreasing penetration depth at both micro and nano-scales. However, the extent of the increase is much more dramatic in nano-scale regime than in micro-scale regime. Hence, as the indentation depth decreases from about 1600 to $200 \mathrm{~nm}$, the hardness increases by a factor of about $0.90-1.22$. Independent zones also have quite similar hardness values for indentation depths between the micro-scale to the nano-scale.

Microhardness, as well, was measured as the function of the residual area (contacted area) after load removal. However, the area function is not considered to be ideal because of blunting in the nanoindentation experiments and such a correction is not considered here. This is sufficient for a relative comparison of the data. The microindentation with a diagonal length about $14 \mu \mathrm{m}$ always crosses a grain boundary. It was found in both microstructures that an indent, which crosses several boundaries, shows lower hardness values. Indents, which cross grain boundaries and precipitations as well as grain boundary of carbides, indicate higher hardness values, corresponding to the fact that an interface increases the hardness. Therefore, the coarse-grained structure (existing among other phases of needle-shaped ferrite) has a higher hardness than the fine-grained structure. Measurements revealed smaller hardness in the centre and higher towards the grain boundary. Typical load progression (load-displacement or $P-h$ ) curves during indentation of $\mathrm{Cu}$ coating, outer and inner layers and steel substrate are shown in Fig. 7.

In the case of cladded materials, the elastic part is recovered upon load removal causing a decrease in the size of the residual area. Consequently, the resulting hardness value (Fig. 8) will appear larger. The nanoindentation trials were therefore specifically designed to investigate tempering induced of facts on individual phases-zones. The in- dentation measurements along the coating cross-section showed that hardness values were lower at the coating side than at the coating-substrate interface (Fig. 7).

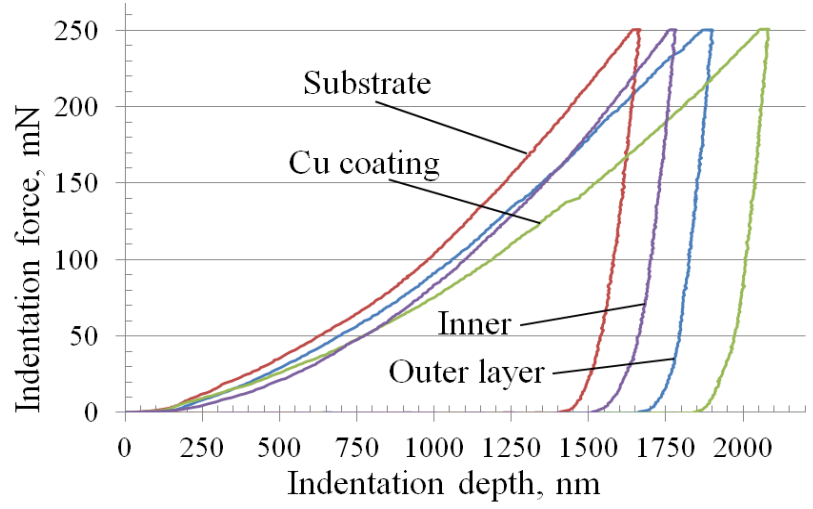

Fig. 7 Depth-force curves of $\mathrm{Cu}$ coating on steel substrate

At a low load of $7 \mathrm{mN}$, the coating demonstrated a hardness value of about $94 \mathrm{MPa}$ at a depth of about $170 \mathrm{~nm}$ which dropped by $15 \%$, e.g., near $10 \mathrm{MPa}$ at a depth of about $2000 \mathrm{~nm}$ for a higher load of $250 \mathrm{mN}$ (Fig. 8).

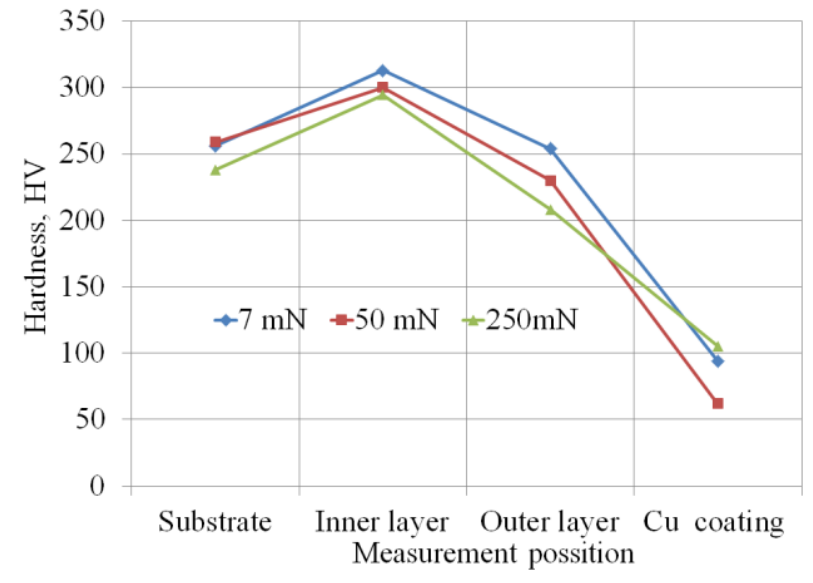

Fig. 8 Hardness testing results of copper coating zones on steel substrate under different loads

Obtained data showed the presence of a strong ISE on the nanohardness behaviour of the coatings. At low indentation load $(7 \mathrm{mN})$, the size of indent was relatively small, whereas the measured hardness values were higher. Under the higher load $(250 \mathrm{mN})$, indentation size was bigger and hardness values smaller, while measuring in the identical areas.

It was defined experimentally that nanoindentation hardness and microindentation hardness have relationship described using a coefficient $k_{1}$ :

$$
H_{\text {nano }}=k_{1} H V \text {, }
$$

where $k_{1}=0.90-1.22$. However, the interpretation of the data is very difficult due to ISE. The ISE is clearly present in single grains, but is absent in fine-grained volumes as indentation size exceeds or is comparable to the grain size.

\section{Conclusions}

1. It was found that for $\mathrm{Cu}$ coating samples the 
nanohardness values were highest for the lowest indenter load of $7 \mathrm{mN}$. At higher indenter loads in the range of 50$250 \mathrm{mN}$, the hardness values decreased. The main difference concerns the comparison between the size of the indentation surface and the size of the heterogeneities of the material. The hetero ratio of the nanohardness $\left(H_{\text {nano }}\right)$ to the microhardness $(H V)$ was smaller in the HAZ, indicating that there is a significant grain-boundary effect.

2. It was found that nanoindentation hardness and microindentation hardnesses are related by the coefficient $k_{1}$. By measuring nanohardness and microhardness in automatic regimes the ISE was not clearly expressed if compared to the conventional hardness testing method.

3. Microhardness is also more sensitive to changes in the microstructure, e.g. recrystallization, than nanohardness. This scale of testing minimizes the potential variations caused by local heterogeneity in submicron structural features. The results show that hardness can no longer be simply compared based solely on the same indenter type and indentation load.

4. Problems associated within the indentation process in nonhomogeneous materials remain a problem that is still under investigation.

\section{References}

1. Oliver, W.C.; Pharr, G.M. 1992. An improved technique for determining hardness and elastic modulus using load and displacement sensing indentation experiments, J. Mater. Res. 7(6): 1564-1583. http://dx.doi.org/10.1557/JMR.1992.1564.

2. Gouldstone, A.; Chollacoop, N.; Dao, M.; Li, J.; Minor, A.M.; Shen, Y.L. 2007. Indentation across size scales and disciplines: Recent developments in experimentation and modelling, J. Acta Mater. 55: 4015-4039. http://dx.doi.org/10.1016/j.actamat.2006.08.044.

3. Lan, L.; Qiu, Ch.; Zhao, D. 2011. Analysis of the hardness and elastic modulus distribution in a high strength steel welded joint by nanoindentation, Advanc. Materials Research 189-193: 3270-3273. http://dx.doi.org/10.4028/www.scientific.net/AMR.189 $-193.3270$.

4. Maier, P.; Richter, A.; Faulkner, R.G.; Ries, R. 2002. Application of nanoindentation technique for structural characterisation of weld materials, Materials Characterization 48(4): 329-339. http://dx.doi.org/10.1016/S1044-5803(02)00274-7.

5. Abu Al-Rub, R.K; Faruk, N.M. 2012. Prediction of micro and nano indentation size effects from spherical indenters, Mechanics of Advanced Materials and Structures 19: 119-128. http://dx.doi.org/10.1080/15376494.2011.572242.

6. Bull, S.J. 2006. Nanoindentation of coatings, J. of Physics D: Applied Physics 38(24): R393-R413. http://dx.doi.org/10.1088/0022-3727/38/24/R01.

7. Voyiadjis, G.Z.; Peters, R. 2010. Size effects in nanoindentation: an experimental and analytical study, Acta Mech. 211: 131-153.

http://dx.doi.org/10.1007/s00707-009-0222-z.

8. Manika, I.; Maniks, J. 2006. Size effects in micro- and nanoscale indentation, Acta Materialia
54(8): 2049-2056.

http://dx.doi.org/10.1016/jactamat.2005.12.031.

9. Atkinson, M. 1995. Further analysis of the size effect in indentation hardness tests of some metals, Journal of Materials Research 10(11): 2908-2915. http://dx.doi.org/10.1557/JMR.1995.2908.

10. BS EN ISO 14577-1: 2015. Metallic materials - Instrumented indentation test for hardness and materials parameters - Part 1: Test method, Int. Standardisation Org., Geneva, Switzerland, 46 p.

11. Aifantis, E.C. 1994. Gradient effects at macro, micro, and nano scales, J. of the Mechanical Behavior of Materials 5(3): 355-375.

http://dx.doi.org/10.1515/JMBM.1994.5.3.355.

12. Qian, L.; Li, M.; Zhou, Z.; Yang, H.; Shi, X. 2005. Comparison of nano-indentation hardness to microhardness, Surface and Coatings Technology 195(23): $264-271$.

http://dx.doi.org/10.1016/j.surfcoat.2004.07.108.

13. Sawa, T. 2010. Correlation between nanoindentation test results and Vickers hardness, IMECO TC3, TC5 and TC22 Conf., Metrology in Modern Context, Pattaya, Chonburi, Thailand, 171-174.

14. Zamfirova, G.; Gaydarov, V. 2003. Influence of the surface effect and scale factor on the microhardness investigation, Proc. of the 10th Int. Conf. on Mechanics and Technology of Composite Materials. Bulgaria.

15. Fischer-Cripps, A.C. 2004. Nanoindentation, 2nd ed., Springer-Verlag LLC, New York, 264 p. http://dx.doi.org/10.1007/978-1-4757-5943-3.

16. Swadener, J.G.; George, E.P.; Pharr, G.M. 2002. The correlation of the indentation size effect measured with indenters of various shapes, J. Mech. Phys. Solids 50(4): 681-694.

http://dx.doi.org/10.1016/S0022-5096(01)00103-X.

\section{S. Baskutis, V. Vasauskas, A. Žunda}

\section{NANO AND MICROHARDNESS TESTING OF HETEROGENEOUS STRUCTURES}

S u m m a r y

The objective of the paper is to compare different hardness measuring methods for the evaluation of mechanical properties in a wide load range $(7-250 \mathrm{mN})$ for heterogeneous structures. Vickers nano and microindentation hardness test was used for mechanical properties assay of chosen samples. Relationships between nanohardness and microhardness were obtained for heat affected zones and fusion zone of the welds and the copper coatings on steel substrates. The experimental results of nano and microindentation tests show correlation with indentation size effect for heterogeneous structures.

Keywords: nanohardness, microhardness, indenter, coating, indentation size effect.

Received November 23, 2015

Accepted March 15, 2016 